\section{QUE CIÊNCIA DA INFORMAÇÃO PRECISAMOS PARA ENFRENTAR A COMPLEXIDADE?}

Resumo: Num encontro científico com a tradição e a consistência como a que este que nos reúne possui, apoiado em especial por todos quantos vêm dedicando trabalho e entusiasmo ao ensino e à investigação em Ciência da Informação, é imperioso que se reflita sobre os desafios que se colocam a esta disciplina, em si mesma complexa, diante de um quadro global de máxima complexidade. Uma disciplina em que faltam consensos entre os seus praticantes e aprendizes a respeito da matriz natural - interdisciplinar ou trans e interdisciplinar? - e do campo mais geral de inserção - as Ciências Sociais ou as Tecnologias da Informação e Comunicação? -, sendo certo que há um défice de debate epistemológico grave que os ENANCIB têm servido para preencher, embora haja necessidade e espaço para muito mais. Pretende-se aqui discutir, no plano interno, externo e formativo da CI, os caminhos que urge traçar e fazer numa Era desafiante como aquela que estamos a viver, partindo de marcos recentes publicados para sinalizar o estado da disciplina em certos panoramas sócio-culturais, nomeadamente o anglo-americano e nórdico-germânico. O apelo à reflexão e ao debate construtivo, se for acatado, é um ganho precioso e vale, por isso, que contribuamos para ele.

Palavras-chave: Ciência da Informação; Complexidade; Era Digital, desafios; Debate epistemológico.

\section{WHAT INFORMATION SCIENCE DO WE NEED TO FACE COMPLEXITY?}

\begin{abstract}
A scientific meeting with tradition and consistency like this that brings us together has supported especially by those who have dedicated work and enthusiasm for teaching and research in Information Science, it is imperative to reflect on the challenges facing this course in itself complex, in front of an overall framework of maximum complexity. A discipline that lack consensus among its practitioners and learners about the natural matrix - interdisciplinary or trans and interdisciplinary? - and the more general field of integration - Social Sciences or Information and Communication Technologies? Giventhatthereis a seriousepistemological debate deficitthat ENANCIB haveservedtofill, althoughthereis a needandroom for more. It is intended here to discuss the internal, external and training plan of the CI the ways that it is urgent to draw and make a was challenging as the one we are experiencing, starting from recent milestones published to signal the state of discipline in certain socio-cultural landscapes, particularly the AngloAmerican and Nordic-Germanic. The call to reflection and constructive debate, if heeded is a precious and worth gain, so that we contribute to it
\end{abstract}

Keywords: Information Science; Complexity; Digital Age, challenges; Debate epistemological. 
Pensada para o encerramento do evento, esta palestra tanto pode acolher um balanço crítico do estado das comunicações expostas e das discussões havidas, como pode erigir-se em estímulo à reflexão, para além do encontro, de modo a que cada um dos participantes consiga entrar em diálogo consigo mesmo e se interrogue sobre o(s) trajeto(s) deste campo disciplinar, até hoje, e que caminho(s) devem ser seguidos sem subterfúgios, nem equívocos diante de uma enorme incerteza e da crescente complexidade que nos envolve. A opção por este segundo objetivo impôs-se naturalmente: não podemos permanecer encerrados no status quo que nos convém e conforta, temos de agitar-nos e formular questões e com isto impulsionarmo-nos em direcção a algo que seja um avanço qualitativo concreto e a garantia de melhor encaixe em face do impacto inesperado do futuro iminente, aqui e agora.

O título é curto e almeja ser claro quanto à preocupação subjacente e dominante. Estamos definitivamente imersos numa densa complexidade, tal e qual Edgar Morin foi mostrando e cartografando ao longo de sua imprescindível e estimulante obra, e, por isso, temos de nos interrogar e buscar consenso sobre que Ciência da Informação praticamos e, ponto decisivo, sobre que ciência precisamos para respondermos aos desafios postos, múltiplos e difíceis.

Não é um desiderato fácil e tentá-lo é um esforço instigante à partida. No entanto, é urgente e entronca em anteriores tentativas, com direito a registo histórico, mas sem impacto claro e directo - o que é estranho, sem dúvida... - na maturação epistemológica do campo.

Recorde-se, antes de mais, que Hans Werllich datou a origem da expressão Information Scienceem 1959, para designar o estudo do conhecimento registado e sua transferência em sentido mais lato. Por sua vez, Anthony Debons fixou, em 1952, no Second International Congress Information Systems Sciences, realizado em Hot Springs (Estado de Virgínia, EUA), o surgimento da expressão a intitular ou nomear uma reunião de cariz internacional.

Não obstante estas duas possibilidades, são inolvidáveis as Conferências realizadas pelo Georgia Institute of Technology, em Atlanta (Georgia, EUA), dias 12 e 13 de outubro de 1961 e 12 e 13 de abril de 1962, com a expressa indicação de se consagrarem ao "treino" dos especialistas em Ciência da Informação (Proceedings, 1962) e aí surgiu a necessidade de trabalhar uma definição atualizada que desse conta de uma revolução emergente - a revolução tecnológica da automatização ou da informática. Jesse H. Shera e Donald B. Cleveland fizeramse eco desse marco definitório no artigo publicado em 1977 e intitulado Historyand fondations 
of Information Science (SHERA; CLEVELAND, 1977). Nunca é demais recordar essa densa definição que condensava todo um programa de desenvolvimento epistemológico para a área com implicações formativas em todos os níveis - graduação e pós-graduação:

Ciência da Informação é a que investiga as propriedades e comportamento da informação, as forças que regem o fluxo da informação e os meios de processamento da informação para um máximo de acessibilidade e uso. $\mathrm{O}$ processo inclui a origem, disseminação, colecta, organização, armazenamento, recuperação, interpretação e uso da informação. O campo deriva ou relacionase com a matemática, a lógica, a linguística, a psicologia, a tecnologia computacional, as operações de pesquisa, as artes gráficas, as comunicações, a biblioteconomia, a gestão e alguns outros campos (cit, por SILVA; RIBEIRO, 2002, p. 53).

Um pouco mais tarde, um psicólogo de formação, Harold Borko (1922-2012) que se tornaria informatólogo (termo proposto por Vickery para designar aquele que trabalha em nível da docência, da investigação e da aplicação prática dos sistemas de informação) e professor de Informação e Documentação, a partir de 1966, na UCLA, Califórnia, EUA, pegou na definição acima e ampliou-a com vista a solidificar melhor a sua concepção integradora da Biblioteconomia e da Documentação, como ramos aplicados da Ciência da Informação. Fê-lo num artigo curto e intitulado Information Science: whatis it?, que veio a ser considerado um "pilar fundamental" para o desenvolvimento da Informação como disciplina científica, dando origem a uma abundante investigação teórica no campo:

Ciência da Informação é a disciplina que investiga as propriedades e o comportamento da informação, as forças que regem o fluxo informacional e os meios de processamento da informação para a optimização do acesso e uso. Está relacionada com um corpo de conhecimento que abrange origem, colecta, organização, armazenamento, recuperação, interpretação, transmissão, transformação e utilização da informação. Isto inclui a investigação, as representações da informação tanto em sistema natural, como no artificial, o uso de códigos para uma eficiente transmissão de mensagens e o estudo dos serviços e técnicas de processamento da informação e seus sistemas de programação.Trata-se de uma ciência interdisciplinar derivada e relacionada com vários campos como a matemática, a lógica, a linguística, a psicologia, a tecnologia computacional, as operações de pesquisa, as artes gráficas, as comunicações, a biblioteconomia, a gestão e outros campos similares. Tem tanto uma componente de ciência pura, que indaga o assunto sem ter em conta a sua aplicação, como uma componente de ciência aplicada, que desenvolve serviços e produtos (...) a biblioteconomia e a documentação são aspectos aplicados da ciência da informação (cit. por SILVA; RIBEIRO, 2002, pp. 53-54). 
A definição composta em 1961-62,e ampliada em 1968, reflecte, desde logo, a existência e extensão de uma nova tecnologia - a "tecnologia computacional", expressão usada nas duas versões - que oferecia um modo completamente diferente e inusitado de proceder às antigas operações de organização, colecta, armazenamento, pesquisa, recuperação e uso da informação, e que ajudava a pôr o foco nas "propriedades" e no "comportamento da informação", nas "forças que regem o fluxo informacional" e nos "meios de processamento da informação para a otimização do acesso e uso", sem que fosse dada, porém, uma explicação sobre esses enigmáticos conceitos e expressões e, mais chocante ainda, sequer fosse adicionado um esclarecimento sobre o que se deveria entender por "informação". Na versão de Borko, pode inferir-se, com segurança, que o novo campo científico assumia um vínculo com a Biblioteconomia e a Documentação, disciplinas precedentes e ramos aplicados da Ciência da Informação, significando isto que aquelas não eram "ciências puras", apenas aplicadas e, por isso, havia um espaço epistemológico a preencher que estava vago - o da indagação de assuntos e de problemas sem a premência imediata de conceber e construir serviços e produtos. A Arquivística e a Museologia foram excluídas do elenco de disciplinas similares com que a nova ciência tinha relações próximas e a razão para isso assenta bastante no senso comum e nas evidências empíricas que dele derivam: a evolução técnica e tecnológica do livro impresso, desde o séc. XV ao séc. XIX, com o aparecimento de vários formatos em papel do livro enquanto unidade textual com princípio, meio e fim e novas espécies como enciclopédias, dicionários, coleções e publicações periódicas (jornais diários e com outras periodicidades, revistas anuais, semestrais, boletins, anais...) determinou a configuração física e operativa da livraria/biblioteca, ou seja, um espaço privado ou reservado ao uso de quem o constituíra, que será convertido por influência régia, eclesiástica e estatal (destaque para o Estado-Nação) em espaço público, acessível ao exercício pleno da cidadania após a Revolução Francesa (e não podem ser omitidos os efeitos práticos da primeira revolução industrial). Novos desenvolvimentos tecnológicos, a partir do último quartel de oitocentos (datação da segunda revolução industrial ou do "imperialismo"), aumentaram a capacidade tipográfica (novas máquinas, novas fontes de energia, maior capacidade produtiva e maior rapidez) com impacto direto no volume, na variedade e na qualidade das publicações, obrigando a melhorar as operações técnicas de tratamento, recuperação, armazenamento e uso e a reconfigurar o espaço físico da consulta - nascerá um novo tipo de serviço ou um novo tipo de biblioteca, designado Centro de Documentação. 
O desafio fora criado, uma vez mais pelo processo histórico, e um homem soube adiantar-se ao seu tempo e construir as respostas necessárias: Paul Otlet (1968-1944), junto com Henri La Fontaine (1854 - 1943) sonhou com um Mundo diferente, de paz e unificado pelo acesso rápido e eficaz a tudo quanto se ia publicando, e para que o sonho fosse concretizado unificou a descrição bibliográfica, criando o Instituto Bibliográfico Internacional, concebeu a famosa Classificação Decimal Universal (CDU) e empenhou-se plenamente na criação e desenvolvimento do Mundaneum, que apesar de várias e graves vicissitudes ficou como um marco antecipador de futuro. Mas, o corolário lógico de uma tão intensa e inovadora atividade consistiu na publicação, em 1934, do Traité de Documentation: le livre surle livre: théorie et pratique, que ostentou em caixa, na folha de rosto e à guisa de sumário geral da obra, um conjunto de tópicos centrais capazes de condensarem todo o extenso conteúdo: "Os livros e os documentos - A leitura, a consulta e a documentação - Redacção, multiplicação, descrição, classificação, utilização dos documentos - Edição e livraria: bibliografia, biblioteca, enciclopédia, arquivos, museografia documental, documentação administrativa - Organismos, organização, cooperação - Oficina e Instituto Internacional de Bibliografia e de Documentação - Rede Universal de Informação e de Documentação" (OTLET, 1996). E expressam o pensamento pioneiro de alguém que, sem conseguir uma sistematização teórica plena, almejou articular sob o conceito abrangente e unificador de documento, desde o manancial bibliográfico, ao arquivístico (“documentação administrativa”) e ao museográfico, abarcando um vasto leque de suportes carregando inscrições simbólicas e sígnicas, e almejou ainda "compactar" algo que a revolução tecnológica do pós-II Guerra Mundial imporia de forma incontornável e surpreendente - a palavra escrita ou falada, a imagem fixa ou animada, o pictórico e escultural:

El objetivo de la documentación organizada es ofrecer para todo tipo de hechos y de conocimientos, informaciones documentadas: $1^{\text {a }}$ universales, encuanto a su objeto; $2^{\mathrm{a}}$ seguras y verdaderas; $3^{\mathrm{a}}$ completas, $4^{\mathrm{a}}$ rápidas; $5^{\mathrm{a}}$ actualizadas; $6^{\text {a }}$ fáciles de obtener; $7^{\text {a }}$ reunidas y preparadas para ser comunicadas; $8^{\text {a }}$ puestas a la disposición del mayor número posible de usuários (OTLET, 1996, p. 411).

O legado teórico e prático de Otlet teve na Bélgica, na França e em Espanha importantes pólos de adesão e difusão e um impacto menor nos Estados Unidos da América, onde a criação, em 1937, do Instituto Americano de Documentação (ADI) teve como fim não tanto difundir as ideias otlelianas, mas sobretudo promover a introdução da tecnologia da microcópia (microfilme), que antecedeu a tecnologia computacional estimuladora direta da Ciência da 
Informação. Temos, assim, que se no contexto europeu sobressai um encadeamento histórico e progressivo de absorção da Bibliotecologia/Biblioteconomia pela Documentação, nos EUA os factos e a literatura a eles referente não coincidem com a "tese" de Borko de que a Biblioteconomia e a Documentação se integrariam no objeto e escopo da Ciência da Informação. O cubano Radamés Linares Columblé sublinha o legado de Otlet (a par da "recuperação da informação") como um dos antecedentes, no séc. XX, da Ciência da Informação, mas, não obstante, reconhece:

La invenciónen 1946 de las tecnologias computacional esfue de progresiva e imediata aplicación en la nasciente esfera, especialmente para solucionar laspreocupaciones dominantes enese lapso de explosión documental sobre cómo localizar y buscar información pontualmente. Conese objetivo se impulsa laelaboración de procedimientos que permitan representar elcontenido de un documento, coincidiendocon El esplendor de las clasificaciones, indizaciones y tesauros (Barreto, 2003, 9).

Para estos fines, Calvin Mooersproponeen 1950 un área que aborde los aspectos intelectuales de ladescripción de información y sus especificaciones para labúsqueda, además de cualquier sistema, técnica o instrumento que se utiliceenlaoperación: larecuperación de información(Seracevic, 1999, 13). (...)

El entramado político y ecnonómico Del cual surge laCiencia de laInformación como disciplina Independiente es posibleresumirloen:

- El crecimiento científico y tecnológico, particularmente el derivado de la Segunda Guerra Mundial, conel incremento exponencial de lainformación.

- El surgimiento de tecnologias, primerolamicrofilmación y ulteriormente lacomputación.

- El carácter estratégico que adquierelainformaciónpara las instancias políticas norteamericanas.

- La explícita confrontación política entre el Este y el Oeste luego Del claro desarrollo científico soviético enelcarrera espacial y enla tecnologia nuclear.

- La supremacia económica norteamericana y lasconsiguientesconcepciones geopolíticas.

Entretanto, lasconceptualizaciones especializadas de insoslayableconmoción para esta ciência fueran:

- El Tratado de la Dcoumentación, Paul Otlet (1935).

- El artículo As we may think, Vannevar Bush (1945).

- La Teoria Matemática de la Communicación, Shannon y Weaver (1948).

- La Recuperación de laInformación, Calvin Mooers (1950). (LINARES 
COLUMBLÉ, 2005, pp. 10-11).

Preso a uma alegada leitura histórica, Radamés Linaresconfirma a naturalidade norteamericana da Ciência da Informação, o que é corroborado em pleno por várias obras dessa origem.

A History of Information Science, 1945-1985 de Dorothy D. Lilley e Ronald.W. Trice embora inclua, em cronologia anexa, a data de 1890 como sendo o começo da Documentação em Europa, 1892 como a data de constituição por Otlet e La Fontaine do Instituto Internacional de Bibliografia, ou 1908 como o ano da criação da Federação Internacional da Documentação em Haia, Holanda, destaca que a "information Science officially replaced documentation in the late 1960's" (LILLEY; TRICE, 1989, p. 1) e acrescenta algo muito interessante:

The architects of information science in the United States wanted to be sure that it would no longer be mistaken either for the microfilm-oriented discipline that documentation had became or for the document-oriented discipline that was library science. This new discipline would be free of real or imagined appendages.

In much of the free world, documentation and library science exist side by side and are sometimes merged in their professional associations and in their publications, as is the case in England. But in the United States there has been no such merger of associations nor of the journals and indexes (LILLEY; TRICE, 1989, p. 1).

Nítida a preocupação de singularizar bem o caso americano, embora no resumo final do capítulo introdutório os Autores tenham explicitamente afirmado:

Lest we forget, information science had its European beginnings as "documentation" in the 1890's. In purpose then was to better serve the documentation needs of scientific investigators. The discipline of documentation was transported to the United States in the 1930's, where it developed along the lines of utilization of film and its reproduction. Information science was to turn that tide since Americans, during the war, had became expert at storing items inexpensively so that they could be reproduced as needed (LILLEY; TRICE, 1989, p. 15).

A Ciência da Informação propunha-se fazer mais e melhor que a Documentação, vinda da Europa, com base nos designados "sistemas de informação não convencionais", ou seja, "sistemas e produtos" imersos em aplicações computacionais e os Autores em foco identificaram um período (1948-1968) de desenvolvimento da disciplina a partir da excitante 
criação de sistemas de busca e de recuperação da informação à imagem e semelhança do "Memex" (1945) de Vannevar Bush (1890-1974). E prosseguiram a sua narrativa historiográfica com a fixação de outros períodos ou fases (não exatamente cronológicos): o da automatização ou informatização de grandes Bibliotecas públicas e especializadas (“aplicação da CI às Bibliotecas"), iniciada ainda no final da década de cinquenta; o da atividade online (1940-1985) centrada na criação e expansão da recuperação online em bases bibliográficas e de texto completo, assim como de catálogos de acesso público online, considerada de "grande revolução"; e, consequentemente, o das redes (1965-1985), que Becker e Olsen, em 1968, definiram como "a interconnection of things, systems, or organizations" e "in na information network than more two participants are engaged in a common pattern of information Exchange through communication for some functional purpose" (LILLEY; TRICE, 1989, p. 103) e que aparece dividido em três subperíodos: o do começo (1965-1971); o do planeamento e desenvolvimento (1972-1978), e o da retracção, descentralização e diversificação (1979-1985) (LILLEY; TRICE, 1989, p.108-132).

Ao concluírem seu texto, já bastante datado é certo, mas valioso pelo contributo sistematizador feito à época, os Autores destacam o que apelidam de "technological climate" ("clima tecnológico") e referem:

There are three key trends related to technology that have persisted throughout this history of information science and that have permeated every conceivable aspectof the discipline and services: (1) the relationship of human to computer; Licklider (1960) started the inquiry in the United States when he submitted his famous symbiosis paper, and Davis, Borgman, Hildreth, and hundreds of others from designers to personal computer users have pondered the problem; (2) the development of the computer network, with ARPANET in the vanguard in establishing a nationwide network, initiating the IMP's, and sharing the unique expert contents that appeal mainly in the research community; and (3) the value-added networks (VANs), which have been the principal means of geographic expansion (LILLEY; TRICE, 1989, p. 140).

Sem dar destaque explícito à CI, mas escolhendo um título poderoso para um volume de quase seiscentas páginas - "Informação: uma história, uma teoria, um dilúvio" - James Gleick começa seu Prólogo evocando uma data, uma teoria e os respetivos pais: o ano de 1948, a "teoria matemática da comunicação" e dois engenheiros e matemáticos dos Bell Telephone Laboratories, Claude Shannon (1916-2001) e Warren Weaver (1894-1978). Começar a história da informação pela criação do "semicondutor eletrônico diminuto" e por uma teoria com posterior e impressionante impacto fora do âmbito das telecomunicações e da eletrônica computacional que a 
justificara, significa alinhamento claro com a simbiose entre esse conceito e a tecnologia emergente no imediato pós-guerra. Nessa teoria apareceu o bit, termo novo, que se juntava à polegada, à libra, ao quarto de galão e ao minuto, e constituía-se como "uma unidade para medir informação", segundo Shannon, "como se houvesse uma coisa, mensurável e quantificável, chamada informação" (GLEICK, 2012, p. 12). O conceito irrompeu simples, destilado e aplicado em bits, para em breve se descobrir que "a informação estava em toda a parte":

A teoria de Shannon estabeleceu uma ponte entre a informação e a incerteza, entre a informação e a entropia, e entre a informação e o caos. Conduziu aos discos compactos e ao aparelhos de faxe, aos computadores e ao ciberespaço, à lei de Moore e todas as Silicon Alleys deste mundo. Nasceu o tratamento da informação, acompanhado pela armazenagem da informação e a recuperação da informação. As pessoas começaram a falar numa sucessora para a Idade do Ferro e a Idade do Vapor: "O homem recoletor de alimentos reaparece estranhamente como recoletor de informação", observou Marshall McLuhan, em 1967. Escreveu isto um pouco cedo demais, no dealbar da informática e do ciberespaço.

Podemos ver agora que a informação é aquilo que faz mover o nosso mundo: o sangue e o combustível, o princípio vital. Impregna as ciências de cima a baixo, transformando todos os ramos do conhecimento.A teoria da informação começou como uma ponte entre a matemática e a engenharia elétrica e daí para a informática. Aquilo a que os anglófonos chamam computerscience é conhecido pelos europeus como informatique, informática e Informatik. Agora, até a biologia se tornou uma ciência da informação, um objecto de mensagens, instruções e códigos. Os genes encerram informação e ativam procedimentos para a ler e escrever.A vida espalha-se mediante a ligação em rede. O próprio corpo é um mecanismo de tratamento de informação. A memória não reside apenas no Cérebro mas em todas as células. Não admira que a genética tenha florescido ao mesmo tempo que a teoria da informação. (...)

John Archibald Wheeler, o último colaborador vivo de Einstein e de Bohr (...) acrescentou: "Todas as coisas físicas são, na sua origem, parte da teoria da informação, e este universo é participativo". Assim, o universo, na sua totalidade, é visto como um computador - uma máquina cósmica de tratamento da informação" (GLEICK, 2012, p. 17 e 19).

Com estas e outras palavras preambulares, Gleick abriu um longo périplo histórico das tecnologias da informação desde os "tambores que falam", passando pela "invenção da escrita", pela "tábua alfabética" (criada por um mestre-escola e pároco de aldeia, Robert Cawdrey, em 1694), pela “máquina analítica” e pela "máquina diferencial” de Charles Babbage (1791-1871), pelo telégrafo "ou sistema nervoso para a terra", pelo telefone da Bell Company, pelo "analisador diferencial" de Vannevar Bush (1890-1974) do Massachusets Instituteof 
Technology, pelo "sistema X", código criptográfico destinado especificamente à comunicação entre Franklin D. Roosevelt e Wiston Churchil (réplica à "máquina Enigma” alemã), pela "máquina de computar fictícia" de Alan Turing (1912-1954), pela "teoria da informação", pelo livro Cybernetics de Norbert Wiener (1894-1964), onde se mostra, enfim, que a informação era uma quantidade tão importante quanto a energia ou a matéria, até ao "pós-dilúvio" ou o "grande álbum de Babel” (GLEICK, 2012, p. 443-472) consubstanciado na Wikipédia, velho sonho iluminista tornado possível através da "galáxia internet" (a "rede das redes").

A mesma saga tecnológica recente é narrada com o foco todo ${ }^{1}$ posto nos protagonistas pelo jornalista Walter Isaacson (autor do best-seller "Steve Jobs"): seu objetivo consistiu em mostrar como um grupo de "hackers, génios e geeks" (ISAACSON, 2016) deram forma e corpo à revolução digital em curso ou à "era dos computadores que aprendem" (learning machines), tópico impactante que nos leva para outra obra de um português, professor nos EUA, Pedro Domingos $^{2}$ The Master Algorithm: howthequest for the ultimate machineswill remake our world (2015), baseado, entre outros, na provocatória e estimulante ideia de que "não há nada que as máquinas não possam fazer"3.

Diante de um panorama desafiador como este onde para e como deve posicionar-se a Ciência da Informação? Sabemos que a especialização científica e tecnológica permitiu que chegássemos onde nos encontramos e este "aqui e agora" é movediço e extraordinariamente dinâmico, envolto em incerteza, mas o que mais perturba e desafia nossa capacidade de pensar e de enfrentar o futuro é a urgência de aprofundar o "trabalho de equipa" num patamar

\footnotetext{
${ }^{1}$ O Autor explica, na Introdução, como nasceu este seu livro e o seu propósito, oportuno e útil, é bastante simples e direto: "O computador e a Internet estão entre as mais importantes invenções da nossa época, embora poucos saibam quem os criou. Não foram engendrados num sótão ou numa garagem por inventores solitários fadados para capas de revista ou para figurar entre os grandes de um panteão, ao lado de Edison, Bell e Morse. A maioria das inovações da era digital, ao invés, foi fruto de trabalho em equipa. Muitas pessoas fascinantes estiveram envolvidas, algumas engenhosas e outras até geniais. Esta é a história desses pioneiros, hackers, inventores e empreendedores - conta quem eles eram, como funcionavam as suas mentes e o que os tornava tão criativos" (ISAACSON, 2016, p. 15). Mas a obra não é uma série cronológica de meras biografias, uma vez que os protagonistas, uns famosos outros esquecidos e até anônimos, surgem enquadrados numa linha evolutiva de inovações tecnológicas: "Ada, Condessa de Lovelace" intitula o capítulo das origens diretas da revolução digital e depois temos "o computador", "programação", "o transistor", "o microchip", "videojogos", "a internet", "o computador pessoal", "software", "online", "a web" e em "Ada para sempre" Isaacson retoma o "sonho" generoso de Lady Lovelace: tornaram-se concretas as máquinas que imaginou, mas, adverte Walter Isaacson, "Nós seres humanos continuamos a ser relevantes numa era de computação cognitiva, dado que somos capazes de pensar de modo diferente, algo que um algoritmo, quase por definição, não consegue dominar" (ISAACSON, 2016, p. 528).

${ }^{2}$ Ver palestra feita a partir de seu livro: Pedro Domingos: "The Master Algorithm" - Talksat Google. Url: https://www.youtube.com/watch?v=B8J4uefCQMc (consultado a 13-8-2016).
}

${ }^{3}$ Ver entrevista que concedeu à “A Revista do Expresso” de 13 de agosto de 2016, p. 22-23. 
epistemológico exigido pelo "regime da complexidade" como tanto insistiu Morin: deixar de fatiar o Mundo e passar a pensá-lo como sistema; evoluir, enfim, da multidisciplinaridade para a inter e a transdisciplinaridade.

Mas, voltemos à questão que nos ajuda a encerrar este primeiro e já longo ponto: será que a CI do artigo de Borko se diluiu na dinâmica tecnológica que a justificou e se deixou absorver pelas Ciências da Computação, pela Informática ou pelos Sistemas da Informação?

A CI das Conferências do Georgia Instituteof Technology (1962-63) e de Harold Borko não ficou submersa pelo processo histórico recente que nos pareceu oportuno e necessário evocar, ainda que de forma impressiva e breve; sobrevive e difunde-se, ainda que com assinaláveis diferenças de acordo com as coordenadas geográficas que utilizemos.

Datado de 2015, editado na Alemanha e escrito por dois alemães, Wolfgang G. Stock e Mechtild A. Stock, o Handbookof Information Science, com novecentas páginas, responde, em parte, à questão formulada. Trata-se de um manual, compêndio ou "trabalho fundamental" sobre CI, destinado a proporcionar uma panorâmica do estado atual dessa disciplina nas suas áreas nucleares: recuperação da informação, representação do conhecimento e infometria. Embora esteja acessível a leitores de diversas profissões e ciências, visa particularmente acadêmicos, praticantes e estudantes de CI, de Library Science (Biblioteconomia/Documentação), de Ciências da Computação, de Gestão da Informação e de Gestão de Conhecimento. Através da sua estrutura, exposta adiante, somos apresentados a uma ciência cujo objeto compõe-se de três domínios teórico-práticos ou de incidência aplicacional, configurando-se naturalmente adaptada ao "espírito" das ISchools, ou seja, do Consórcio Internacional ${ }^{4}$ (envolve o "ramo" norteamericano e o "ramo" europeu) de Escolas de Informação vocacionado para desenvolver este campo científico e suas adjacências, em particular a Tecnologia da Informação, a Library Science, a Informática, a CI e outras. Pode-se mesmo admitir que o manual se destina, naturalmente, a ser usado nesse espaço amplo e influente de ensino e investigação.

Mas, antes de entrarmos no cerne desta CI, herdeira direta da Documentação de Paul Otlet (a Biblioteconomia ou Library Science aparece, apenas, relacionada como disciplina vizinha, estatuto que não é atribuído nem à Arquivística, nem à Museologia, o que permite inferir que elas são vistas pelos Autores, seguindo, aliás, "doutrina" coincidente, como “distantes") e, sobretudo, da Information Science norte-americana, convém determo-nos um

\footnotetext{
${ }^{4}$ Ver a este respeito o website http://ischools.org/ (consultado em 14-8-2016). 
pouco sobre o entendimento dos Autores a respeito da disciplina que estudam e praticam.

Wolfgang e Mechtild Stock, na Parte A do seu manual, introduzem o leitor na CI, começando por definir a disciplina e seguidamente tratando tópicos que evidenciam a sua perspetiva epistemológica: conhecimento e informação; informação e compreensão/interpretação (hermenêutica); documentos; e literacia informacional. E, voltando ao princípio, os Autores reconhecem não existirem definições consensualmente aceites de CI e invocam para isso a juventude da disciplina por comparação com outras (como a Matemática ou a Física) e o facto de ela estar fortemente interrelacionada com várias disciplinas, como a Tecnologia da Informação e Economia, cada uma das quais com grande ênfase em suas próprias definições, mas, não obstante a falta de uma definição clara, entendem e reafirmam que a CI é, por um lado, empregue para diferentes propósitos de investigação fundamental (ou pura) e, por outro, em dimensão aplicada. E adiantamumadefinição "de trabalho" ouoperatória: "Information Science studies the representation, storage and suply as well as the search for and retrieval of relevant (predominantly digital) documents and knowledge (including the environment of information)". (STOCK; STOCK, 2015, p. 3)

Se rapidamente compararmos esta definição com a de Harold Borko ressalta, de imediato, um recorte maior do objecto nesta dos Autores alemães, com o foco posto no estudo do modo de representar, armazenar e fornecer/recuperar documentos e conhecimento relevantes (predominantemente digitais, com uma leve referência ao "ambiente informacional". De fora ficou o propósito de estudar "as propriedades e comportamento da informação, as forças que regem o fluxo da informação e os meios de processamento da informação para um máximo de acessibilidade e uso", objectivo mais ambíguo, mas também mais ambicioso do ponto de vista epistemológico na medida em que agrega uma dimensão social e humana, "qualitativa", ao processamento tecnológico e instrumental da informação.

Apesar do recorte feito, os Autores estão em linha com a vocação interdisciplinar das definições de 1961/62 e 1968, indicando, com precisão, aquelas com as quais se relaciona estreitamente (apresentam, para tanto, uma figura que não é a famosa "flor" de Le Coadic, nem os diagramas de Silva e Ribeiro, mas parece cumprir uma função similar): a CI está no centro e à sua volta figuram, como disciplinas vizinhas, as Ciências da Computação, a Economia, a Biblioteconomia. Linguística (ramo Computacional), a Pedagogia e a Ciência da Ciência (ou Sociologia da Ciência/Comunicação Científica). Temos, assim, um círculo interdisciplinar 
estreito que choca, sobretudo, por várias ausências e evidencia a presença forte das Ciências e da Tecnologia centradas no processamento e na recuperação lógica e computacional da informação. Há, assim, uma preferência clara pelo diálogo com disciplinas que contribuem diretamente para o que eles chamam as "sub-disciplinas" da CI ou, talvez mais apropriadamente, facetas do seu objecto de estudo:

(1)Recuperação da Informação;

(2)Representação do Conhecimento;

(3)Gestão de Conhecimento e Literacia da Informação;

(4)Pesquisa no interior da Sociedade da Informação e dos Mercados da Informação;

(5)Infometria, incluindo Ciência da Web (ou Webmetria).

Estas facetas decorrem do sentido plasmado na definição, e os Autores tiveram o cuidado de explicar, com algum detalhe, os elementos nela usados:

- Representação: o conhecimento contido nos documentos. Tal como os documentos em si (a saber: artigos científicos, livros, patentes ou publicações corporativas, mas também websites ou postagens em microblogues), condensado através de curtas descrições textuais e etiquetas com importantes termos e conceitos tendo em vista a filtragem de informação (STOCK; STOCK, 2015, p. 3-4):

- Armazenamento e "serviço": os documentos são processados de tal maneira que sejam idealmente estruturados, mais facilmente recuperáveis e legíveis e armazenados em locais digitais, em que possam ser geridos (STOCK; STOCK, 2015, p. 4); p. 4);

- Busca ou pesquisa: CI observa como os utilizadores satisfazem as suas necessidades de informação, analisa as formulações de resposta a questões postas em ferramentas de busca e analisa ainda o modo como eles utilizam a informação encontrada (STOCK; STOCK, 2015, p. 4);

- Recuperação: os pontos focais da CI são os sistemas para pesquisa de conhecimento, de que avultam como exemplos proeminentes os motores de busca na internet e também os catálogos de biblioteca;

- Relevância: o objetivo não é encontrar "qualquer velha" informação, mas somente a espécie de conhecimento que ajuda o utilizador a satisfazer as suas necessidades informacionais (STOCK; STOCK, 2015, p. 4); 
- Predominantemente digital: desde o advento da internet e da informação comercial e industrial, amplas áreas do conhecimento humano estão acessíveis digitalmente, mas apesar da informação digital ser o tema nuclear ou "o core" da CI, há ainda espaço para as coleções de informação não-digital (STOCK; STOCK, 2015, p. 4);

- Documentos: são textos e objetos não textuais (por exemplo, imagens, música e vídeos, mas também factos científicos, objetos económicos, objetos em museus e galerias, factos em tempo real e pessoas), sempre físicos (STOCK; STOCK, 2015, p. 4); e

- Conhecimento: na CI o conhecimento é visto como qualquer coisa estática, fixada num documento e armazenada numa memória, armazenamento que pode ser digital (a $W W W$ - World WideWeb), material (uma Biblioteca) ou física (o cérebro dos "funcionários de uma empresa"), ao passo que a informação sempre contém um elemento dinâmico, pois alguém informa (activo) ou é informado (passivo), e como a produção e o uso do conhecimento estão profundamente embebidos no processo social e cultural a CI tem um forte contexto cultural (STOCK; STOCK, 2015, p. 4).

Esta explicação da definição adotada esclarece bastante o leitor e ajuda ao posicionamento crítico que segue nos próximos dois pontos. Para complementar, vejamos a estrutura da obra que é muito expressiva e desenvolve-se apenas em dois eixos (a infometria embora considerada uma das subdisciplinas da CI não é abordada no manual de forma destacada): (1) a recuperação da informação; e (2) a gestão do conhecimento. O primeiro estende-se por um conjunto articulado e equilibrado de "capítulos": história, fundamentos e tipologia da recuperação de informação; processamento de linguagem natural; sistemas booleanos de recuperação; modelos clássicos de recuperação: recuperação de informação na web; problemas especiais da recuperação; e investigação empírica nesta área através da análise infométrica, de ferramentas e métodos analíticos, do perfil de utilizador e uso na pesquisa e avaliação dos sistemas de recuperação.

O segundo, por sua vez, compreende um capítulo "introdutório" sobre a origem e a evolução desta área, seguindo-se os metadados, as folksonomias, os sistemas de organização do conhecimento, métodos de texto-orientado em organização de conhecimento, indexação, elaboração de sumários e investigação empírica na área através da avaliação dos sistemas de organização do conhecimento e da avaliação da indexação e da elaboração de sumários. 
A súmula possível da obra mostra a afirmação de uma CI que incorporou a Documentação de Paul Otlet, mas, mantém autonomia face à Biblioteconomia e apesar de ser aceite uma noção de documento bastante ampla que inclui os objetos de Museu, a Museologia e a Arquivística nem sequer vizinhas são. Também é curioso notar a recusa de um tecnologismo ou instrumentalismo da CI, sendo prestada atenção ao comportamento dos utilizadores e às suas necessidades informacionais, assim como ao contexto cultural de produção e ao uso da informação e do conhecimento, a orientação dominante do manual acaba na pesquisa empírica sobre recuperação da informação e sobre os aspetos relacionados com a organização/representação do conhecimento, o que representa um reducionismo epistemológico porque limita a capacidade expansiva da CI como disciplina passível de ser inscrita no campo das Ciências Sociais.

\section{O PROBLEMA EPISTEMOLÓGICO}

O contributo recente dos Autores alemães, sendo muito importante quanto à sistematização que propõe e à atualização evidenciada no plano tecnológico e aplicacional, parece algo regressivo se considerarmos tanto a definição de Harold Borko, quanto o esforço adaptativo feito por Yves-François Le Coadic no "manual de bolso" que fez para a coleção “Que sais-je?” das Presses Universitaires de France, intitulado Ciência da Informação (1994; tradução brasileira 1997). Neste caso, a par de algumas semelhanças óbvias e importantes como, por exemplo, aceitar o mesmo ponto de partida, ou seja, uma ciência "que tivesse por objeto de estudo a informação, ou seja, uma ciência da informação, bem como uma tecnologia e técnicas resultantes das descobertas feitas por essa ciência" (LE COADIC, 1997, p. 2), aceitar a origem norte-americana da CI e acolher a sua natureza interdisciplinar, bem cartografada na "famosa flor", cuja "corola" é ocupada pelo objeto informação + comunicação, estudado cientificamente através de vários procedimentos metodológicos e conceitos operatórios, e trabalhado, em dimensão prática, pelas "técnicas bibliotecárias e documentárias"; e ao redor um conjunto de disciplinas com afinidades concretas com a CI, a saber: a Psicologia, a Linguística, a Sociologia, a Informática, a Matemática, a Lógica, a Estatística, a Eletrônica, a Economia, o Direito, a Filosofia, a Política e as Telecomunicações. É ainda semelhante a vinculação "genética" da CI à Documentação, mas Le Coadic foi mais longe, indicando como "primeiras disciplinas" ou antecessoras diretas da CI, além da 
Documentação, a Biblioteconomia, a Museoconomia e o Jornalismo, ficando de fora a Arquivística (LE COADIC, 1997, p. 14-21). No entanto, até nas semelhanças ressaltam as diferenças e, desde logo, a preocupação do Autor francês em apresentar a CI como uma ciência social com acentuada vertente cultural, à luz da tradição iluminista francesa, definir informação como "um conhecimento inscrito (gerado) sob a forma escrita (impressa ou numérica), oral ou audiovisual" (LE COADIC, 1997, p. 5), o que o levou a especificar a relação semântica estreita entre informação, conhecimento e, também, comunicação, e situá-la num projecto interdisciplinar específico, com a chancela científica e intelectual de Robert Escarpit (1918-2000), de Roland Barthes (1915-1980) e de Jean Meyriat (1921-2010), nascido em 1974 e designado, desde então, Ciências da Informação e Comunicação, agregando docentes, especialistas/práticos, investigadores e académicos da Sociologia à Documentação com vista a formar um modelo formativo graduado e pós-graduado em França. O livro de Le Coadic destinou-se a ser guia no seio da interdisciplina CIC, mas não conseguiu impor-se diante da aceleração vertiginosa da "revolução informacional" em curso, nem tão pouco atacar o problema epistemológico subjacente a todo este processo.

Um problema que, em parte, é discutido pelo Autor cubano, já atrás citado, e que importa apresentar nas suas linhas essenciais, porquanto ele é decisivo no debate que propomos sobre a CI de que precisamos hoje e no futuro que está chegando.

Simplificando um pouco, podemos referir que Radamés Linares Columblé aborda este problema, sobretudo, trazendo à colação o confronto entre o positivismo e os paradigmas explicativos e interpretativos e em que "trincheira" está a CI e a natureza interdisciplinar desta disciplina com implicação epistemológica direta no tipo de conhecimento produzido.

A respeito do positivismo e suas alternativas vale a pena seguir os termos precisos do Autor:

- Así, hay autores que sostienen que la epistemologia positivista gobierna El pensamiento de los investigadores más sérios em Bibliotecología y Ciencia de la Información (enlos EEUU). Sin embargo, esta epistemologia ha sido ampliamente enfrentada y sus valores reinterpretados em las ciências sociales como mismo em las ciências naturales. Por tanto, no es deseableen LIS. Existe, por em dela necesidad de repensar los fundamentos epistemológicos de la 
investigaciónen esta disciplina profesional y considerar las aproximaciones cualitativas sugeridas por las investigaciones emprendidas, por ejemplo, dentro de la teoria crítica y de la hermenêutica (Harris, 1986, 516).

- Otros piensan que la investigaciónen Ciencia de la Información aborda problemas de diferente tipo que requieren diferentes métodos de investigación, focalizados por diferentes métodos del conocimiento o epistemologias. En lugar de defender un único fundamento epistemológico, se de bereconocerla validez equivalente de diferentes formas de conocimiento, o de descubrir, que deben caracterizar a la investigaciónen Ciencia de la Información (Schrader, 1984: 370). (...)

- La Ciencia de la Información se plante a su pertenencia a las ciências sociales, ante todo, como una expresión de las transformaciones de finale de siglo XX, etapa que se cuestionala hegemonia del conocimiento científico de corte positivista, cuandolas ciências sociales se distancian de ese modelo y cuando la información como fenômeno es comprensible solo si se inserta en determinados espacio seconómicos, sociales y culturales (LINARES COLOMBLÉ, 2005, p. 39-40).

A CI do recente manual alemão não é enfaticamente exposta como uma ciência social e suas ligações e valências tecnológicas sobressaem aí. O contrário, pois, da perspectiva, ainda forte e com larga tradição no campo, de vê-la como ciência social e humana, resistente, por consequência, a concepção positivista e demasiado instrumental/técnica, abertaao exercício da crítica histórica e económico-social e à hermenêutica. Há, assim, uma tensão entre perspectivas opostas e o campo sofre com o impasse que se arrasta e impede superações à altura dos desafios que o tempo atual coloca. Que tipo de ciência social pode e deve ser a CI? A resposta a esta questão ajuda, claramente, a enfrentar e superar o problema epistemológico.

E prende-se ou articula-se, estreitamente, com o tópico da natureza interdisciplinar da CI destacado pelo Autor cubano. Radamés reconhece que a interdisciplinaridade impõe-se, nomeadamente nas ciências sociais, para contrariar a tendência fragmentadora e segmentadora da realidade, ajudando a criar espaços de conhecimento mais abrangente e menos fragmentado: "No es posible enfrentar El estúdio del segmento de larealidadproprio de la Ciencia de la Información sin la contribuición de conceptos, procidimientos y teorias 
provenoentes de otras áreas cognoscitivas que interceptan la información" (LINARES COLOMBLÉ, 2005, p. 41). No entanto, o mesmo Autor observa, apoiando-se em Tefko Saracevic, que as relações interdisciplinares com a CI estão pouco fundamentadas e faltam estudos empíricos sobre cada um dos elos: "Por tanto, hasta ahora y lamentablemente, aunque el caracter interdisciplinario de esta área es incuestionable, la relacion ocurre em un solo sentido y no puede afirmar se como influyela Ciencia de la Información em otras áreas de conocimento" (LINARES COLOMBLÉ, 2005, p. 41).

Estamos perante uma ponta relevante do problema epistemológico que, aqui, se pretende deixar delineado. Com efeito, criou-se um grande equívoco a respeito da vocação interdisciplinar da CI, porque se assume que esta disciplina tem de auxiliar todas as disciplinas e saberes, dado o cariz transversal da informação. Daí a ideia já aplicada à Documentação, entendida como "ciência da Ciência", ou seja, organizava e tornava acessível a informação produzida e usada por cada área de conhecimento científico. Trata-se de uma relação unívoca e, portanto, não tem retorno: o que é que as ciências beneficiadas fornecem à CI para esta melhorar e reforçar a sua capacidade investigativa? Que diálogo verdadeiramente interdisciplinar se estabelece entre elas?

É também importante ter presente que a multi, a inter e a transdisciplinaridade correspondem a dinâmicas próprias da construção e do desenvolvimento do trabalho científico. Imaginar cada ciência a explorar o seu respetivo segmento de realidade, sozinha, sem estabelecer contactos, nem relações com outras que se mostrem próximas ou com afinidades quanto ao método ou ao objeto, não é sequer possível num paradigma vincadamente positivista e especializado. As disciplinas, ao longo de sua trajetória própria, fazem contactos e trocas de informação entre si, o que configura naturalmente uma dinâmica multi ou pluridisciplinar, em que não se coordenam pesquisas comuns, mas tão somente prestação pontual de "serviços" como, com alguma liberalidade, se pode dizer que é o papel da CI e, antes dela da Documentação, da Biblioteconomia, da Arquivística e até da Museologia, na organização e na acessibilidade a documentos/informação, face às disciplinas que deles necessitam. Outras e profundas implicações tem a dinâmica interdisciplinar que obriga a um planejamento comum de pesquisa, intercâmbio de procedimentos metodológicos e arsenal conceitual-teórico, na partilha de problemas e de casos comuns: a alegada vocação interdisciplinar da CI deveria pressupor este perfil, mas as abordagens sérias do problema, 
como a de Radamés LinaresColomblé, mostram que tal não passa de uma meta ideal a atingir e, assim sendo, são infundadas todas as reflexões epistemológicas que partem deste pressuposto, nomeadamente a abordagem pós-modernista que convive bem com a ideia de "vazio epistêmico", ou seja, a ausência na CI de um corpo teórico-metodológico exclusivo, homogêneo e sólido, de condições internas concretas associadas a condições externas para formar uma "episteme" visível e perene. Por fim, radical é a dinâmica transdisciplinar que possibilita ir além do diálogo interdisciplinar e chegar a um nível de partilha de métodos, conceitos e resultados intenso e profundo que pode levar a um cruzamento ou até uma fusão das disciplinas envolvidas e atravessadas por este tipo de dinâmica. É sabido que a inter e a transdisciplinaridade combinam bem com a natureza das Ciências Sociais e correspondem a paradigmas anti-positivistas, o que as coloca em rota de adesão aos desafios da complexidade. Mas, no que à CI diz respeito, vimos que uma destas duas dinâmicas representa um desejo ainda não alcançado, e a outra nem chega sequer a ser postulada seriamente.

Podemos, assim, tentar caracterizar o problema epistemológico nos seus principais aspetos, recorrendo ao esquema que concebemos e vimos afinando, baseado num ensaio de sistematização.

Em primeiro lugar, é possível identificar, na literatura produzida e na prática epistémica observável, duas concepções gerais ou perspectivas que encerram a reflexão crítica sobre a pluralidade de disciplinas sequenciais e autónomas - a Biblioteconomia, a Documentação e a Ciência da Informação, excluídas ou não desta sequência a Arquivística e a Museologia - e sobre o plural da expressão "Ciências da Informação" que significa a assunção de uma interdisciplina, cujos limites e funcionamento seria conveniente precisar, pois não o tem sido. Temos referido duas: a perspectiva cumulativa, ou fragmentada, e a evolutiva.

Na primeira, cabe a defesa objetiva da pluri ou multidisciplinaridade que se formou historicamente com o aparecimento de disciplinas profissionais e práticas subordinadas, dentro da triunfante lógica positivista de oitocentos, à História, à Filologia e à Erudição Literária - a Arquivística, a Museologia e a Bibliotecologia/Biblioteconomia - e determinadas por "lugares de memória" ou instituições culturais criadas pelo Estado-Nação como reserva eterna para as narrativas identitárias - o Arquivo, a Biblioteca e o Museu. O incremento da industrialização obrigou as sociedades e os estados a aderirem a novas soluções e a 
Documentação ou "ciência do documento" de Paul Otlet teve de surgir na sequência da segunda revolução industrial e seus efeitos tão espectaculares, quanto dramáticos (18701945). E a "terceira vaga", que se seguiu, trouxe consigo a CI. Traçamos uma linha de sucessão disciplinar que a perspectiva ou concepção cumulativa ou fragmentada respeita e interpreta como um conjunto de instâncias/respostas diferentes para espaços físicos e suportes materiais distintos, convergentes numa idêntica função/missão: guardar, organizar e disponibilizar documentos para quem os quisesse ou precisasse de consultar ou apreciar. Uma interpretação legitimada pelo senso comum e por um raciocínio corporativo ou de sobrevivência natural: continuando a haver bibliotecas, arquivos e "documentos de arquivo" e museus, não há razão para duvidar da permanência das disciplinas relacionadas e dos seus titulares/praticantes. E a revolução digital em curso abana, mas não chega para destruir a tradição que se mantém pela força revitalizadora das palavras: passamos a ter Biblioteca Digital, Arquivo Digital e Museu Digital. A respectiva materialidade é completamente outra, mas continua a ser possível transferir para ela as funcionalidades "clássicas" ou procedentes das instituições/serviços que imperaram na Modernidade (sécs. XVIII-XX). As disciplinas coexistem, exibem vizinhança (a noção de "disciplinas vizinhas" aparece no recente manual de Wolfgang e Mechtild Stock, que pode ser incluído nesta perspectiva) e encontram até um eventual rejuvenescimento através do recurso a discursos epistemológicos pós-modernistas.

Na segunda, isto é, na evolutiva, sobressai a tendência para pôr de lado a pluri ou multidisciplinaridade e valorizar o potencial fecundante do binômio inter e transdisciplinaridade, através da noção de evolução. Sendo dinâmicas, estas modalidades processuais de trabalho científico comunicam entre si e transformam, causam mudança e metamorfose: a pluralidade de disciplinas surgidas nestes três últimos séculos têm sido encaradas de maneira estática, apesar das suas relações e semelhanças, e fechada cada uma sobre si mesma, o que é paradoxal e contaria o princípio de progressão aplicado ao conhecimento científico em geral, portanto parece óbvio admitir que elas podem sofrer evolução e passarem todas, em conjunto, para um estádio de interdisciplinaridade. A "tese" da interdisciplina parece (mas é apenas aparência...) corresponder a um efetivo salto epistemológico. No entanto, para que este se verifique, as disciplinas não podem cristalizar-se numa imutável interdisciplinaridade, porque tal situação é contranatura opondo-se ao inevitável: a mudança. E esta chega com a transdisciplinaridade que traz em si cruzamento de saberes, alterações de estado e fusões disciplinares. Na concepção evolutiva, a CI pode deixar de ser 
mais uma disciplina que surgiu numa conjuntura histórica determinada, tal como as anteriores e teria de ficar intacta como alegadamente elas ficaram, para, ao invés disto, se tornar a síntese das anteriores, a simbiose construtiva dos principais legados teóricos e empíricos que elas puderam fornecer a fim de que uma nova ciência, mais consistente, mais homogênea, mais eficiente e capaz pudesse, enfim, constituir-se. Faz sentido, sem dúvida, mas não escapa a oportunos e pertinentes questionamentos: tendo-se chegado, evolutivamente, ao estádio da CI, este será o último? A dinâmica inerente à Ciência não poderá reforçar uma tendência, que há cada vez mais gente a promover, para a integração ou fusão da CI com os Sistemas de Informação, as Ciências da Computação e outras disciplinas conexas? E a mesma dinâmica não poderá, também e em alternativa, seguir uma via que leve à proposta complexa e ousada da Cibersemiótica de SorenBrier, definida como teoria transdisciplinar de informação, cognição, comunicação significantee interacção entre natureza e cultura (BRIER, 2008)? Muito menos credível e, por isso, carecido de melhores análises é o novo rumo que alguns apontam para a CI - inserir-se nas denominadas Humanidades Digitais ${ }^{5}$.

Em segundo lugar, é preciso dar toda a relevância ao debate sobre os paradigmas, debate introduzido de forma séria e impactante, para a área, por Rafael Capurro, precisamente no ENANCIB realizado na Escola de Ciência da Informação da Universidade Federal de Minas Gerais, Belo Horizonte, Brasil, em 2003. Na palestra, logo publicada em espanhol, intitulada Epistemologia de laCiencia de laInformación (CAPURRO, 2003), identificou três paradigmas, correspondendo o primeiro - o físico - à Documentação de Paul Otlet e os dois seguintes - o cognitivo e o social - situados dentro da CI. A noção de paradigma foi colhida em Thomas Kuhn (1922-1996) e usada por Capurro num sentido demasiado estrito, que temos questionado, embora a noção em si nos pareça válida e operatória, apesar de objeções entretanto surgidas, como a de Miguel Rendón Rojas, que mostra preferência pelo conceito de Imre Lakatos (1922-1974) "programa de pesquisa" (MOREIRA; MASSONI, 2011). Mas, o mais crucial não é examinar a consistência dos dois conceitos operatórios, é estranhar a escassez de contributos para o debate e a reflexão sobre os paradigmas na área da documentação/informação: antes da aportação de Capurro, encontramos, em obra de José Maria Izquierdo Arroyo, a proposta de paradigmas pré e pro-otlelianos (MORENO

\footnotetext{
${ }^{5}$ Nos dias 8 e 9 de outubro de 2015 realizou-se na Faculdade de Ciências Sociais e Humanas da Universidade Nova de Lisboa o Congresso de Humanidades Digitai em Portugal: construir pontes e quebrar barreiras na era digital. Ver respetivo website, url: http://www.fcsh.unl.pt/submissao-de-artigos-cientificos/congresso-dehumanidades-digitais-em-portugal-construir-pontes-e-quebrar-barreiras-na-era-digital (consultado, 15-8-2016).
} 
FERNANDEZ; IZQUIERDO ALONSO, 2014) e a partir de 2004, mais consistentemente, Armando Malheiro da Silva e Fernanda Ribeiro postularam a existência de dois paradigmas: o custodial, patrimonialista, historicista e tecnicista; e o pós-custodial, informacional e científico (SILVA; RIBEIRO, 2011; e SILVA; RIBEIRO, 2012). Mais recentemente, em intervenções orais avulsas começou a ser admitida a inclusão entre os dois do paradigma sócio-cultural, tendo em conta a realidade brasileira e da América do Sul, em que a Teoria Crítica e a Sociologia exercem ainda uma influência direta e forte na actividade e nas reflexões de bibliotecários, museólogos e cientistas da informação. $O$ entendimento de paradigma, para estes Autores, é muito menos estrito e visa aproximar-se de algumas definições de Kuhn (diferentes, é certo, de outras tecidas pelo mesmo): paradigma é um modo de ver e de pensar enformado por um conjunto coerente de princípios, teorias, conceitos e método partilhados por uma ou mais gerações de cientistas através de auto-reprodução formativa e prática de pesquisa. Trata-se, pois, de um modo de ver e de pensar científicos, o que legitima a pergunta sobre se o paradigma custodial formatador de arquivistas, bibliotecários, museólogos e documentalistas correspondia a um efetivo estádio científico ou, pelo contrário, era mais um pré-paradigma, porquanto a Arquivística, a Biblioteconomia, a Museologia e a Documentação não possuíam os requisitos internos da Ciência? A resposta dos Autores justifica haver já paradigma propriamente dito, mas não decorrente dessas disciplinas essencialmente práticas e dominadas pelo senso comum, antes emanado da História e da Filologia, cujo estatuto científico permitiu-lhes até criar, sob a égide positivista, uma constelação de "ciências auxiliares", ou seja, recursos de apoio metodológico. Paradigma, gerado e alimentado "internamente", somente o pós-custodial, informacional e, por isso, assumidamente científico, que se mantém emergente, isto é, coexiste com o custodial e o sócio-cultural, e que só faz realmente sentido para os defensores ou simpatizantes da conceção ou perspectiva evolutiva acima exposta.

Em terceiro e último lugar, não pode ser evitado o exame cuidadoso das opções metodológicas praticadas em cada uma das disciplinas referidas, incluindo a CI (mas de certidão norte-americana e escopo demasiado tecnológico), ou debatidas no seio de uma CI trans e interdisciplinar, regida pelo paradigma pós-custodial e justificada pela concepção evolutiva. Qual o método da Arquivística, da Biblioteconomia, da Documentação, da Museologia e da CI (versão americana)? A resposta tem sido plural e, geralmente, frágil, porque associar a noção de método científico com operações intelectuais e técnicas/tecnológicas de 
representação conceitual, de organização e de armazenamento para a recuperação e uso não colhe um amplo assentimento epistemológico, na medida em que essas operações não se apresentam como meios de descoberta científica, mas já como modos ou maneiras de solucionar ou de atender a demandas concretas. Daí a proposta, em 1999 pensada para a Arquivística "reconfigurada" como "uma Ciência da Informação" e, a partir de 2002, endereçada direta e enfaticamente à CI, de um Método científico, colhido no campo das Ciências Sociais e aplicável à CI trans e interdisciplinar de modo a conferir coerência e consistência ao correlato paradigma pós-custodial. Referimo-nos ao Método Quadripolar, adaptado com esta designação por Armando Malheiro da Silva e Fernanda Ribeiro de um estimulante, mas frustrado, projecto metodológico para as Ciências Sociais, exposto em livro de 1974, por três sociólogos belgas: Paul De Bruyne, Jacques Herman e Marc De Schoutheete, professor e assistentes na Universidade de Lovaina $^{6}$. E se o considerarmos um contributo sério e necessário, convém, urgentemente, intensificar o debate em torno de se verificar se estarmos ou não perante uma solução forte para uma parte do problema epistemológico em análise.

\section{AS EXIGÊNCIAS DA COMPLEXIDADE}

Chegados a este ponto não se espere um receituário que alivie todos quantos se têm angustiado com o arrastar e o adensar do problema epistemológico da CI. No entanto, é razoável exigir que seja lançada alguma claridade sobre o caminho difícil, mas inevitável, que a Era atual impõe que se descubra e siga com firmeza.

Para tanto há que retornar a Edgar Morin, de forma, aliás, muito simplificada e breve, pois a sua obra e pensamento são sobejamente conhecidos e tratados. À crise da Ciência moderna e do positivismo, dramaticamente evidenciada pela II Guerra Mundial, Morin ergueu, a partir de um caudal vasto de influências e contribuições, um ideal de regeneração do conhecimento humano através de uma espécie de "macro paradigma" - o do pensamento sistémico e complexo ou, mais simplesmente, o paradigma (macro ou transversal a todas as

\footnotetext{
${ }^{6}$ Editado por Presse Universitaire de France-PUF com o titulo Dynamique de la recherche en Sciences Sociales. Sobre Autores, obra e adaptação/aplicação na CI em Portugal ver número especial "Método Quadripolar, 40 anos". Prisma.Com, n. 26 (2014). Url: http://revistas.ua.pt/index.php/prismacom/issue/view/231 (consultado 14-8-2016).
} 
ciências e muitos saberes) da complexidade.

Hoje é trivial incluir a presença da complexidade em todas as reflexões e debates sérios sobre as múltiplas facetas da realidade humana e social, sobre o futuro próximo do nosso planeta e a fascinante e ousadíssima exploração do cosmos, pelo que não é sequer admissível querer aprofundar e tentar resolver o problema epistemológico da CI sem o articular com as exigências postas, no pós-Modernidade (nova Era, portanto), pela complexidade, ou seja, pela oposição estruturada às visões lineares, parcelares, fragmentadoras da realidade, ao primado da especialização que nega e impede a "religação dos saberes", à persistência das antinomias como a da Natureza versus Cultura, ao império da pluri ou multidisciplinaridade que ainda ofusca os esforços sérios de vivências interdisciplinares, quando, na verdade, deveria ser imperativo natural pensar e pesquisar transdisciplinarmente... Neste sentido, é possível elencar um conjunto de quesitos a ter em conta, se entendermos que a CI trans e interdisciplinar, esboçada atrás, é também ela, em parte, filha ou consequência da Era Digital ou da Era da Informação, segundo o sociólogo catalão Manuel Castells, há décadas fixado na Califórnia e, mais precisamente, no "olho do furacão" do ímpeto tecnológico em curso, Silicon Valley ou Vale do Silício, e como tal desafiada diretamente pela complexidade inerente ao processo histórico global (e globalizado) que estamos a viver. A própria expressão, que a nomeia, surgiu condicionada pela teoria matemática de Shannon e Weaver e pela tecnologia computacional e telemática, o que traduz uma conotação clara ao universo científico e técnico responsável direto por este processo. É, aliás, inegável este vinculo histórico, mas ele não se substitui à enorme influência que a complexidade exerce sobre a natureza e o destino no futuro próximo da CI.

Há, assim, a necessidade de fixar um roteiro de questionamentos e de reflexões que possa abranger a comunidade de profissionais e de cientistas em nível mundial, porque não parece ser mais possível fugir ou negar urgência na resposta séria e esforçada às exigências da complexidade. E o roteiro que propomos assenta num conjunto de tópicos que ressaltam como claramente prioritários.

O primeiro pode ser ilustrado a partir de um exemplo muito sugestivo que colhemos na missão pós-custodial do arquivista brasileiro Charley Luz de colocar a Arquivística a abraçar, autonomamente, a nova realidade das plataformas digitais e a moldá-las segundo seus princípios e práticas "ancestrais", daí o título sugestivo de seu último livro "Primitivos 
digitais: uma abordagem arquivística" (LUZ, 2015), em que, logo no início, afirma: uma "possível Arquivologia 2.0 trataria da arquitetura da informação, da arquitetura de interface, sabendo a utilidade dos portais corporativos, da taxonomia e da folksonomia" (LUZ, 2015, p. 17). Sem dúvida, uma meta ousada e avançada para a Arquivística, mas poderá a sua concretização operar-se desprezando, no mínimo, um diálogo interdisciplinar com, pelo menos, a CI plasmada no manual de Wolfgang e Mechtild Stock? Basta, tão só, entrarmos no estudo e na aplicação/uso das plataformas digitais para se perceber que é contranatura evitar as dinâmicas inter e transdisciplinar, que se impõem, de imediato, no terreno do processamento, gestão, fluxo, comunicação, busca e uso infocomunicacionais. A informação/documentação jurídico-administrativa e corporativa, vista como única, autêntica e probatória na tradição arquivístico-diplomática, ao nascer digital e, sobretudo, ao ser arquitetada e estruturada para efeitos de uma recuperação baseada, por exemplo, em ontologias e folksonomias não se diferencia, substancialmente, de outras tipologias e abre-se, assim, um espaço comum de estudo e de trabalho aplicado, potencialmente transdisciplinar, em que Arquivística, Documentação, Museologia e CI mais do que convergem: esse espaço potencia a inevitabilidade de uma instância científica única, capaz de enfrentar os problemas e os temas atuais que urge resolver.

O segundo tópico é alimentado pelo exemplo fornecido pelos Autores alemães, supracitados, que não contemplaram, na figura das relações de vizinhança da CI com outras disciplinas, a presença da Arquivística ou da Museologia. Ao contrário de Le Coadic, bem mais generoso no elenco de relações interdisciplinares, e de Harold Borko que ampliou o leque um pouco mais, em 1968, Wolfgang e Mechtild Stock foram restritivos, arriscando uma deriva demasiado tecnológica, o que pode representar um retrocesso epistemológico grave: o regresso a uma lógica positivista oposta ao pensamento sistémico e complexo, que não prepara a CI para se afirmar como disciplina indispensável nesta Era da Informação em que já estamos imersos.

O terceiro tem a ver com a ameaçadora sombra de retrocesso que paira, também, sobre a noção de documento: não se pode afirmar a importância e permanência operatória desta noção e, ao mesmo tempo, diminuir-lhe a amplitude, ao contrário do que fez Paul Otlet para quem o documento ia do livro impresso a uma pintura, passando por ofícios, processos administrativos, relatórios de contas ou imagens, discos, etc. E este rasgo inovador permitiu a discípulos, como Suzanne Briet (1894-1989), mediante o seu "famoso antílope", integrar os objetos e as coleções dos museus na noção de documento. Como também não se pode jamais 
opor documento a informação/conhecimento, dado que é cada vez mais evidente ser aquele o resultado imediato de todo e qualquer processo intencional de registo (para potencial comunicação) deconteúdos (ideias, emoções...) num suporte material. Para robustecer este enfoque, foi formulada e proposta, em 2002, a seguinte definição de informação: "conjunto estruturado de representações mentais codificadas (símbolos significantes) socialmente contextualizadas e passíveis de serem registadas num qualquer suporte material (papel, filme, banda magnética, disco compacto, etc.) e, portanto, comunicadas de forma assíncrona e multidireccionada" (SILVA; RIBEIRO, 2002, p. 37). Em vez de antinomias redutoras e equivocadas, deve imperar o impulso para aproximações e simbioses semânticas que enriquecem e aprofundam. Por isso, não é exagerado considerar o documento como epifenómeno da informação e da comunicação, dois conceitos complementares e indissociáveis, embora distintos, que se reportam a um fenômeno humano e social que não cabe apenas, e muito menos se esgota, no "mecanicismo" da teoria de Shannon e de Weaver ou no "fisicalismo" redutor das TIC -Tecnologias da Informação e Comunicação.

O quarto consiste em chamar a atenção para as implicações formativas dos preceitos relativos ao pensamento sistémico e complexo: a formação graduada e pós-graduada não pode continuar desarticulada, como sucede no Brasil, em que, contrariando abertamente as demonstrações patentes na vasta obra de Edgar Morin, graduam-se ou licenciam-se profissionais, separadamente, em Biblioteconomia/Documentação, em Arquivística e em Museologia, para seguidamente oferecer-se a possibilidade de uma formação pós-graduada (nível de Mestrado e de Doutoramento) em Ciência da Informação, em que se admite a imposição de uma exigência teórico-metodológica consentânea com a essência do conhecimento científico. Subsiste nesta orientação um pensamento confuso e errático sobre profissão e ciência, observável no modelo formativo praticado não apenas no Brasil, mas em muitos países no mundo. Se é verdade que nem toda a profissão deriva de um corpus científico que a valide e justifique, também é óbvio não fazer sentido separar, em níveis de ensino, de acordo com uma suposta descriminação negativa (o nível inicial não reúne condições para "comunicar" epistemologicamente com os níveis superiores ou subsequentes), a formação profissional da científica, propriamente dita. À luz da complexidade, o caminho parece ser de uma efetiva e sistémica integração formativa transversal, inclusive, a conjuntos disciplinares mais ou menos homogêneos.

O quinto decorre do anterior, no sentido de apresentar como inadiável a regularização e até a formalização de práticas de diálogo inter e transdisciplinar, tendo em vista o sucesso 
educativo na área e a excelência do desempenho profissional, envolvendo as disciplinas do campo documental e infocomunicacional. Arquivistas, bibliotecários, documentalistas, museólogos e gestores de informação precisam aprofundar e radicalizar o espírito de uma iniciativa muito interessante e pioneira, ocorrida, em São Paulo, de 17 a 22 de março de 2002 - o $1^{\circ}$ Congresso Internacional de Arquivos, Bibliotecas, Centros de Documentação e Museus, seguido de um segundo Congresso realizado, também, em São Paulo, de 25 a 29 de junho de 2006, e de um terceiro, de novo em São Paulo, de 19 a 21 de julho de $2016^{7}$. Radicalizar tornando mais curta a periodicidade e abrindo, claramente, o espaço de comunicações, pôsterese mesas redondas a contribuições conjuntas, isto é, resultantes de pesquisas e de reflexões pelos vários tipos de profissional e de especialista reunidos no evento. Só desta forma se garante um efetivo diálogo cruzado entre eles, com frutos e consequências transformadoras. Eis, aqui, uma indiscutível exigência da complexidade.

O sexto incita a uma análise sistemática e o mais exaustiva possível da proposta portuguesa da CI trans e interdisciplinar (SILVA; RIBEIRO, 2002; SILVA, 2006; CASTRO; MELO; SEABRA; e COSTA, 2011). Trata-se de uma proposta epistemológica ambiciosa e difícil, porque tem vindo a ser concretizada em vários planos ao mesmo tempo: no plano educativo (em nível de graduação e pós-graduação - Mestrado e Doutoramento), no plano investigativo (através da participação numa unidade de investigação, o CETAC.Media Centro de Estudos em Tecnologia e Ciências da Comunicação, agora em vias de integração num projeto institucional mais robusto) e no plano estratégico-académico (pautado pelos esforços de aproximação, no seio da própria Faculdade de Letras da Universidade do Porto, da CI às Ciências da Comunicação, o que conduziu à existência, atualmente, do Departamento de Ciências da Comunicação e da Informação, bem como a tentativa interinstitucional de instaurar, em Portugal, algo parecido com as Ciências da Informação e da Comunicação lançadas há quarenta e dois anos em França). Uma proposta que joga dialeticamente com as duas dinâmicas para a reconfiguração interna e externa da CI: a transdisciplinaridade deve ser atingida e praticada, finalmente, como corolário lógico da perspectiva evolutiva, ou seja, todas as disciplinas práticas centradas, cada uma à sua maneira, no documento/informação cruzam-se e fundem-se convertendo a CI em uma instância científica mais enriquecida pelos legados teórico-empíricos recebidos e mais fortalecida; e a vocação interdisciplinar tão

\footnotetext{
7 Sobre estes eventos, assumidos pela FEBAB - Federação Brasileira de Associações de Bibliotecários, Cientistas de Informação e Instituições, e respetivo conteúdo ver os seguintes websites: https://sigarra.up.pt/fcnaup/pt//pub_geral.pub_view?pi_pub_base_id=10661; http://basessibi.c3sl.ufpr.br/brapci/index.php/article/view/0000014343/4de2eb69dc38fc57b81cc730253fdd5f; e http://integrar.febab.org.br/ .
} 
propalada é reafirmada, mas exige-se que seja exercitada, nos dois sentidos e não apenas unívoca como equivocadamente tem sido defendida e praticada, em círculos disciplinares mais ou menos afins ou correlatos, não merecendo dúvida a prioridade concedida às relações fecundas e fecundantes com as Ciências da Comunicação, as Ciências Sociais (sem exclusões), as Ciências da Computação e os Sistemas de Informação. A tendência é para que estas relações se intensifiquem e possam ser contaminadas pela dinâmica transdisciplinar, o que vai plenamente de encontro ao "macro paradigma" da complexidade.

O sétimo relaciona-se com o anterior e convoca a problemática do impreciso e da dimensão qualitativa ou interpretativa, que os Autores alemães do HandbookofInformation Science (2015) não negaram, mas em cuja definição operatória está pouco evidente, ao invés da definição que usamos: "Ciência da Informação é uma ciência social que investiga os problemas, temas e casos relacionados com o fenômeno infocomunicacional perceptível e cognoscível através da confirmação ou não das propriedades inerentes à gênese do fluxo, organização e comportamento informacionais (origem, colecta, organização, armazenamento, recuperação, interpretação, transmissão, transformação e utilização da informação" (SILVA, 2006, p. 141). Em linha com este posicionamento, há que discutir a "tese" de Rafael Capurro de que a hermenêutica é imprescindível à CI e é preciso, também, pegar seriamente na semiótica de Charles SandersPeirce (1839-1914) e na semiologia francesa e trazê-la para o exame intersticial da informação e não apenas da comunicação como se tornou habitual. Um estudo oportuno e importante para precisar melhor as relações da CI com as Ciências da Comunicação.

O oitavo põe em pauta a preservação tradicional em papel e, em particular, a digital, o que conduz diretamente ao trinómio " informação - documento - memória “, que compõe, sem hesitações, o objeto da CI, ou seja, os problemas e temas que lhe são específicos. É, porém, sabido que a problemática da preservação é multi/pluri e interdisciplinar, na medida em que os aspetos relacionados com a boa conservação química e ambiental do suporte papel ficam fora do escopo da CI, como já escapava à Arquivística, à Biblioteconomia, à Documentação e à Museologia a capacidade de analisá-los e resolvê-los. E é também óbvio que a construção e as anomalias do suporte eletrônico-digital não são do âmbito próprio da CI, obrigando-a a um diálogo permanente neste domínio com as Ciências da Computação, a Electrotecnia e a Informática. Temos, aqui, um bom exemplo de complexidade: a informação, o documento e a reprodução humana e social da memória são assunto/problema de pesquisa da CI, mas do ponto de vista do senso comum aparecem amarrados à materialidade, ao suporte e às questões científico-técnicas da preservação física, só que tanto uma como outra 
abordagens, apesar de complementares, diferem entre si, baseando-se em opções metodológicas distintas - interligam-se e fecundam-se, sem se anularem.

O nono tópico introduz o inconclusivo e equivocado debate sobre o "fim do livro" ou ainda a "crise das bibliotecas", convertidas em espaços de convívio e de multiusos, $\mathrm{Na}$ verdade, o que precisamos discutir, à luz da complexidade, é o binômio cérebro - leitura, cada vez mais exposto ao impacto tecnológico detectado, com progressiva nitidez, nos exames imagiológicos cerebrais. E a discussão aprofunda-se e enriquece-se com a evolução do hipertexto e a navegação em rede, na internet, impulsionada, em larga medida, pelos motores de busca e consubstanciada num processo cognitivo e social novo, mais amplo e complexo - a "metaleitura", que consiste no exercício polifuncional ou simultâneo de ler texto, ouvir e ver imagens legendadas ou "faladas", produzir e enviar/receber mensagens... O Homo Sapiens que está a exibir cada vez mais este perfil está a ganhar e a perder competências, supera-se e, ao mesmo tempo, desequilibra-se cognitivamente, sendo este um problema sério que tem de ser enfrentado e resolvido e a CI trans e interdisciplinar tem de implicar-se nele plenamente.

O décimo e último incide sobre a volumosa e intensa investigação aplicada em interfaces, arquitetura de informação e usabilidade que envolve um cada vez maior número de disciplinas e de saberes que naturalmente interagem muito dentro da dinâmica da interdisciplinaridade, mas evidenciando, também, propensão transdisciplinar. E, neste fértil campo intercientífico, o papel da CI tem de ser melhor assinalado e desenvolvido a partir de um legado empírico e teórico que começou com os estudos de utilizador e desembocou no atual domínio do comportamento informacional, ou mais apropriadamente, infocomunicacional, uma vez que é imperioso ampliar o enfoque e atender não apenas às atitudes e às necessidades do sucedâneo do "leitor clássico", mas também ao consumidor (hoje convertido cada vez mais em "prossumidor") de notícias de imprensa e de ciberjonalismo, radiofónicas e televisionadas, de programas de entretenimento e desportivo, de musicais, de publicidade, etc.

Percebe-se, facilmente, que estes dez tópicos não esgotam o roteiro que foi possível apresentar, assim como cada um merece ser desenvolvido e examinado com detalhe, mas, aqui, o propósito, além de vincar bem a pergunta que figura no título, provocar em todos um desassossego saudável e mobilizador, um desejo de romper com zonas de conforto teóricas ou essencialmente corporativas e enfrentar o Mundo radicalmente complexo em que vivemos.

\section{REFERÊNCIAS}


BRIER, Soren. Cybersemiotics: why information is not enough. Toronto: University of Toronto Press, 2008.

CAPURRO, Rafael. Epistemología de la Ciencia de la Información, 2003. Disponível em website de Rafael Capurro. url:http://www.capurro.de/enancib.htm(consultadoem 15-8-2016).

CASTRO, António; MELO, Cecília; SEABRA, Pedro; COSTA, Ricardo M. O Curso de LicenciaturaemCiência da Informação: dezanos de actividadepedagógica e científica. Porto: Universidade do Porto, 2011.

GLEICK, James. Informação: uma história, uma teoria, um dilúvio. Lisboa: Circulo de Leitores, 2012.

ISAACSON, Walter. Os Inovadores. Porto: Porto Editora, 2016.

LE COADIC, Yves-François. A Ciência da Informação. Brasília, DF: Briquet de Lemos Livros, 1997.

LILLEY, Dorothy D.; TRICE, Ronald W. A History of Information Science, 1945-1985. San Diego:

Academik Press, Inc., 1989.

LINARES COLUMBLÉ, Radamés. Ciencia de laInformación: su historia y epistemologia. Bogotá: Rojas Eberhard Editores, 2005.

LUZ, Charley. Primitivos digitais: uma abordagem arquivística. Salvador: 9Bravos, 2015.

MOREIRA, Marco António; MASSONI, Neusa Teresinha. Epistemlogias do século XX. São Paulo: EPU, 2011.

MORENO FERNANDEZ, Luis Miguel; IZQUIERDO ALONSO, Mónica. El Pensamiento de José Maria Izquierdo Arroyo en la organización y representación del onocimiento:

unasistematizacióndesdefundamentosfilosóficos y semióticos. Scire: Representación y Organzación del Conocimiento. Zaragoza,vol 20, 1, p. 22-31, 2014.Disponível em:

http://www.ibersid.eu/ojs/index.php/scire/article/view/4195/3763 (consultado em 14-8-2016).

OTLET, Paul. EI Tratado de Documentación: el libro sobre el libro, teoria y práctica. Múrcia: Universidad de Múrcia, 1996.

PROCEEDINGS of the Conferences on Training Science Information Specialists: October 12-13, 1961 [and] April 12-13, 1962, Georgia Institute of Technology, Atlanta, Georgia. Atlanta: Georgia Institute of Technology, National Science Foundation (U.S.), 1962.

SHERA, Jesse H.; CLEVELAND, Donald B. History and foundations of Informtion Science. Annual Review of Information Science and Technology. Washington, n. 12, p. 249-275, 1977.

SILVA, Armando Malheiro da. A Informação: da compreensão do fenómeno à construção do objecto. Porto: Edições Afrontamento, 2006.

SILVA, Armando Malheiro da; RIBEIRO, Fernanda. Das "ciências" documentais à ciência da informação: ensaioepistemológico para um novo modelo curricular. Porto: Edições Afrontamento, 2002.

SILVA, Armando Malheiro da; RIBEIRO, Fernanda. Paradigmas, serviços e mediações em Ciência da Informação. Recife: Nectar, 2011.

SILVA, Armando Malheiro da; RIBEIRO, Fernanda, Documentation/Information and their paradigms; characterization and importance in research, education and professional practice. Knowledge Organization: International Journal. Wurzburg, 39, n. 2. p. 111-124, 2012.

STOCK, Wolfgang G.; STOCK, Mechtild. Handbook of Information Science. Berlin: Walter de Gruyter, 2016. 